\title{
Photosensitivity in Thiopyronine-resistant Yeast Mutants
}

\author{
By JULIA M. ANDERSON* AND ROBERT M. ROTH \\ Department of Biology, Illinois Institute of Technology, Chicago, Illinois 60616, U.S.A.
}

(Received 6 April 1982; revised 16 June 1982)

\begin{abstract}
In yeast, thiopyronine (TP) acts both as a growth inhibitor (in the dark) and a photodynamic sensitizer (in the light). We have isolated a large number of TP-resistant mutants of Saccharomyces cerevisiae and characterized them by genetic and photobiological techniques. Resistance to the growth-inhibitory (dark) effects of TP can arise by mutations in at least four separate genes. Growth-inhibitory and photodynamic effects of TP can be genetically separated, as evidenced by the finding that resistance mutants affected in three of the genes were not altered in their photodynamic response to the dye. In contrast, a mutation in the fourth gene simultaneously conferred high resistance to both the growth-inhibitory and photosensitizing effects of TP, suggesting that a mutation had occurred at a step common to the expression of both effects. Preliminary data suggest that this mutation reduces the ability of the cells either to take up, or bind, TP.
\end{abstract}

\section{INTRODUCTION}

Photosensitization occurs when a cell is treated with certain dyes and exposed to light; the light energy is absorbed by the dye (photosensitizer) and transferred to other molecules either outside or inside the cell. The end result is cellular damage and cell death (Spikes, 1977).

In humans the application of light to sensitizer-treated cells has resulted in dramatic clearing of skin lesions in psoriasis and other skin disorders (Parrish et al., 1974; Wolff et al., 1976). Unfortunately, the sensitizers currently used interact with DNA in vivo with possible mutagenic and carcinogenic effects, raising serious questions about the long term safety of the therapy (Stern et al., 1979; Farber, 1980). The problem could be overcome, however, by identifying photosensitizers that effectively inactivate eukaryotic cells by attacking only non-nuclear targets. TP appears to be such a sensitizer. Early physiological and genetic studies utilizing Saccharomyces cerevisiae suggested that TP acts photodynamically by inactivating cytoplasmic rather than nuclear targets (Marquardt \& von Laer, 1966; Lochmann et al., 1976; NishiyamaWatanabe, 1976) [photosensitization which involves molecular oxygen in the photochemical process is specifically referred to as photodynamic action]. Recent studies at the molecular level support the earlier work by showing that nuclear DNA remains intact in yeast photosensitized by TP while the binding of cytoplasmic mRNA to ribosomes is reduced (Lochmann et al., 1981).

In addition to its photosensitizing effects, TP is also fungicidal to yeast growing in the dark. Since both the fungicidal and photodynamic effects of TP would be potentially useful in the treatment of fungal skin infections in vivo, it is important to characterize fully the interaction of TP with eukaryotic cells.

In a previous report (Roth et al., 1978) we isolated a single mutant resistant to the growthinhibitory effects of TP and showed that the resistance property was under simple genetic control. For this report we isolated a large number of TP-resistant mutants to determine whether

Abbreviations: RC, respiratory competent; RD, respiratory deficient; TP, thiopyronine. 
more than one gene controlled resistance and also to examine whether TP resistance genes had any effect on TP-sensitized photodynamic killing.

\section{METHODS}

Yeast strains and culture conditions. The properties of the parental and mutant strains are given in Table 1. The parental strains were obtained from the Berkeley Yeast Genetic Stock Center. Strains were routinely maintained on solidified YEPDX complex medium containing, $\mathrm{l}^{-1}: 10 \mathrm{~g}$ yeast extract, $20 \mathrm{~g}$ peptone, $20 \mathrm{~g}$ glucose, $26 \mathrm{~g}$ agar, $10 \mathrm{mg}$ L-histidine, $20 \mathrm{mg}$ L-tryptophan, $200 \mathrm{mg}$ DL-threonine, $20 \mathrm{mg} \mathrm{L}$-phenylalanine, $60 \mathrm{mg}$ L-isoleucine, $60 \mathrm{mg} \mathrm{L}$ lysine, $50 \mathrm{mg}$ L-tyrosine, $20 \mathrm{mg}$ L-arginine, $60 \mathrm{mg}$ L-leucine, $10 \mathrm{mg} \mathrm{L}$-methionine, $78 \mathrm{mg} \mathrm{L}$-valine, $10 \mathrm{mg}$ uracil and $10 \mathrm{mg}$ adenine. Prior to each experiment the strains were grown on YEPDX for $12-18 \mathrm{~h}$ at $30^{\circ} \mathrm{C}$.

Thiopyronine. TP. $\frac{1}{2} \mathrm{ZnCl}_{2}$ (mol. wt 422.5 ) was supplied by Merck, and used without further purification.

Determination of respiratory competence. Yeast strains utilizing acetate as the sole source of carbon were considered respiratory competent (RC). Those unable to utilize acetate were considered respiratory deficient (RD). In genetic crosses, strains with the RD phenotype always behaved as typical mitochondrial $r h o^{-}$derivatives, but we made no attempt to characterize them in detail. In some experiments we isolated RD derivative strains by selecting for 'petite' colony morphology on YEPDX medium.

The respiratory ability of yeast strains was determined on a complex medium (ACE) using $1 \%(w / v)$ potassium acetate as the carbon source [a medium similar to the pre-sporulation medium of Roth \& Fogel (1971) except that it contained L-leucine and DL-threonine at $60 \mathrm{mg}$ and $300 \mathrm{mg} \mathrm{1}^{-1}$, respectively].

Isolation of TP-resistant mutants. The properties of the TP-resistant mutants are given in Table 1. KP24, a RC mutant, was isolated from a TP-sensitive strain (A364A) following mutagenesis with UV light as described previously (Roth et al., 1978). RD mutants R350-8 and R650-4 were isolated by spreading TP-sensitive RC strains (X2180-1A or X2180-1 B, 2.5 $\times 10^{6}$ cells per plate) on YEPDX media containing 118, 178 or $237 \mu \mathrm{M}$-TP. After one week in the dark $\left(30^{\circ} \mathrm{C}\right)$, the resistant colonies were isolated and purified on YEPDX medium without TP. Each presumptive mutant was tested for its level of TP resistance in quantitative growth-inhibitory assays and for its ability to grow on ACE medium. R80, a RC mutant, was isolated from X2180-1B. The isolation procedure involved growing the parental strain in liquid ACE medium for $12 \mathrm{~h}\left(30^{\circ} \mathrm{C}\right.$, with shaking), followed by passage to ACE containing $12 \mu \mathrm{M}$-TP. After $4 \mathrm{~d}$ the cells were transferred to ACE medium without TP. Subsequent passages, at $3 \mathrm{~d}$ intervals, were made to ACE medium containing increasing concentrations of TP, namely $24,59,118,189$ and $237 \mu \mathrm{M}$. The final culture growth was isolated and purified on solidified ACE medium without TP at $30^{\circ} \mathrm{C}$. The purified presumptive mutant (R80) was tested in a quantitative growth-inhibitory assay for its level of TP resistance.

Measurement of growth-inhibitory effects of $T P$ in the dark. Both quantitative and qualitative growth inhibition assays were used to measure the fungicidal activity of TP. For the growth-inhibitory assay in liquid medium an overnight culture of the test organism grown on YEPDX was inoculated $\left(5 \times 10^{5}\right.$ cells per tube) into a series of tubes $(14 \times 125 \mathrm{~mm}$ ) each containing $5 \mathrm{ml}$ glucose synthetic complete medium (GSC; Roth \& Dampier, 1972)

Table 1. Properties of $S$. cerevisiae strains

(A) Parental strains

$\begin{array}{lcccc}\text { Strain } & \begin{array}{c}\text { Mating } \\ \text { type }\end{array} & \begin{array}{c}\text { Nutritional } \\ \text { requirements }\end{array} & \begin{array}{c}\text { thp } p^{\mathrm{R}} \\ \text { gene }\end{array} & \begin{array}{c}\text { Respiratory } \\ \text { phenotype }\end{array} \\ \text { X2180-1A } & \mathbf{a} & \text { None } & + & \text { RC } \\ \text { X2180-1B } & \alpha & \text { None } & + & \text { RC } \\ \text { A364A } & \text { a } & \text { Adenine, uracil, histidine } & + & \text { RC } \\ & & \text { lysine, tyrosine } & & \end{array}$

(B) Thiopyronine-resistant mutants

\begin{tabular}{llcc} 
Mutant $\dagger$ & \multicolumn{1}{c}{ Parent } & Resistance genes & $\begin{array}{c}\text { Respiratory } \\
\text { phenotype* }\end{array}$ \\
KP24 & A364A & $T H P^{\mathrm{R}} 1$ & RC \\
R350-8 & X2180-1A & $t h p^{\mathrm{R}} 2-1$ & RD \\
R650-4 & X2180-1B & $t h^{\mathrm{R}} 3$ & RD \\
R80 & X2180-1B & $t h p^{\mathrm{R}} 2-2 T H P^{\mathrm{R}} 4$ & RC
\end{tabular}

\footnotetext{
* The RC phenotype is defined as the ability to use acetate as the sole source of carbon and the RD phenotype as the inability to do so.

$\dagger$ All mutants retained the parental mating type and nutritional phenotype.
} 
buffered to $\mathrm{pH} 5$ with potassium acid phthalate $(0.05 \mathrm{M})$ and containing increasing concentrations of TP. The experimental cultures were grown for three days on a shaker $\left(300\right.$ r.p.m.) in the dark at $30^{\circ} \mathrm{C}$. Growth was measured in a Klett-Summerson colorimeter (600 $\mathrm{nm}$ filter) against appropriate blanks containing GSC and TP to correct for red dye and was expressed as a percentage of growth in the absence of TP (cell control).

A growth-inhibitory assay on solid medium was also used. This qualitative assay proved to be an efficient way of comparing the growth-inhibitory effects of TP when using large numbers of spore segregants from genetic crosses. Four types of solidified media containing TP were used: (1) a minimal medium (MIN) containing $2 \%$ (w/v) glucose and $0.67 \%(\mathrm{w} / \mathrm{v})$ yeast nitrogen base without amino acids (Difco); (2) a synthetic complete medium (COMP) containing the components of MIN plus the amino acids and bases added to YEPDX; (3) YEPDX; and (4) ACE.

Direct replica plating of colonies to medium containing TP was not sufficiently sensitive for scoring the TPresistant phenotype; therefore, overnight cultures of the test organisms grown on YEPDX were suspended in 50 $\mathrm{mM}-\mathrm{KH}_{2} \mathrm{PO}_{4}$ buffer $(\mathrm{pH} \mathrm{6.8)}$ and adjusted to $25 \mathrm{Klett}$ units $(600 \mathrm{~nm})$. This suspension was diluted 100 -fold in buffer and $0.02 \mathrm{ml}$ of the dilution (usually $1.5 \times 10^{3}$ cells) placed on the test medium. In this way eight different spore segregants could be assayed on one plate at cell concentrations that permitted the TP-resistant and TPsensitive phenotypes to be clearly distinguished. Work was carried out in semi-darkness once the cells were exposed to TP. Plates were incubated at $30^{\circ} \mathrm{C}$ in the dark. The results were recorded when TP-resistant and TPsensitive controls, included in each assay, showed the appropriate response (usually after 3-4 d).

Measurement of photodynamic killing with TP. The assay of Roth et al. (1978) measures cell killing during exposure of dye-treated, aerated cells to light. We modified this method as follows: (1) the experimental sample was placed in a footed glass dish $(100 \times 15 \mathrm{~mm})$ surrounded by a water bath $\left(30^{\circ} \mathrm{C}\right)$ connected to a constant temperature circulator (Haake Instruments), and (2) prior to each assay the intensity of the light source was monitored with a radiometer (Yellow Springs Instrument, Model 65A) and adjusted to a predetermined value by raising or lowering the light source above the sample dish. These modifications reduced variability between experiments. Viability was expressed as the number of surviving colonies (on YEPDX medium) at a particular illumination time divided by the number of colonies in the sample prior to illumination. Cell viability was not significantly reduced when cells were exposed either to dye in the absence of light or to light in the absence of dye.

Genetic analysis. Standard techniques (Sherman \& Lawrence, 1974) were used to mate haploids and to recover and sporulate the resulting hybrids. Following treatment with 'Glusulase', asci were separated with a micromanipulator and grown into spore clones. Segregation of the mating type genes served to monitor normal meiotic events. Sensitivity or resistance to TP was scored as described above.

Complementation Test. Complementation tests on recessive thp $p^{\mathrm{R}}$ (TP resistance) genes were performed in the usual way by crossing strains carrying different $t h p^{\mathrm{R}}$ mutations and testing diploids for their ability to grow in the growth-inhibitory solid medium assay.

\section{RESULTS AND DISCUSSION}

\section{Isolation and characterization of TP-resistant mutants}

TP at low concentrations inhibits the growth (in the dark) of $S$. cerevisiae. Previously (Roth $e t$ al., 1978), we isolated a single TP-resistant mutant and established that resistance was under genetic control. For this report we isolated 40 spontaneous TP-resistant mutants by plating sensitive wild-type strains on solid media containing various concentrations of the dye. While the parental strains were RC, all the resistant mutants were RD, defined, for our purposes, as an inability to utilize acetate as a carbon source.

The level of TP resistance in each of the presumptive mutants was measured in a quantitative growth inhibition assay. The presumptive mutants fell into three groups based on their level of TP resistance; the data from one or more mutants of each group is shown in Fig. 1(a). At the highest concentration of TP tested $(24 \mu \mathrm{M})$, a mutant of the highly resistant type (R350-8) showed $95 \%$ of the control growth, a representative of the moderately resistant group (R650-4) showed $59 \%$ and the least resistant type showed $3 \%$. Those with the least resistance closely resembled the parental strain (X2180-1B; Fig. $1 b$ ) and were not used further.

All of the above TP-resistant mutants were RD. To test whether TP resistance could be obtained in a mutant that retained the $\mathrm{RC}$ character during growth in medium containing $\mathrm{TP}, \mathrm{a}$ medium containing the dye and acetate as the sole carbon source (ACE) was used to select for a TP-resistant mutant. Only a strain that was both RC and TP resistant would grow in this medium. A wild-type strain (X2180-1B) was transferred sequentially to increasing concentrations of TP in ACE medium (see Methods). The final isolate (R80) was indeed both RC and TP- 

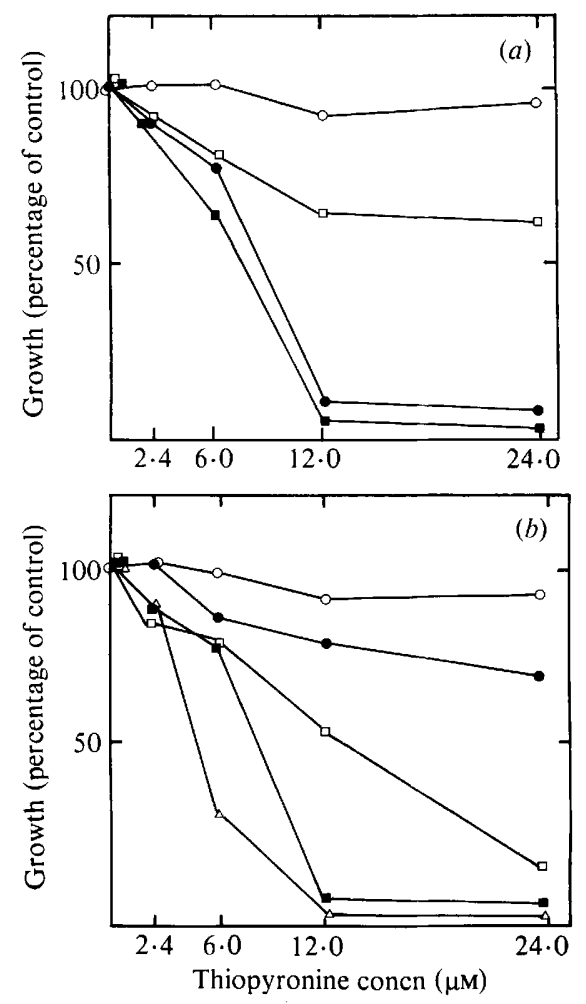

Fig. 1. Growth-inhibitory effects of TP on yeast cells growing in the dark. The TP-resistant mutants and parental strains were inoculated into tubes of GSC containing the indicated concentrations of TP, and a control tube without TP. The cultures were placed on a shaker $\left(300\right.$ r.p.m.) for $3 \mathrm{~d}$ at $30^{\circ} \mathrm{C}$ in the dark. (a) The RD, TP-resistant mutants were isolated on YEPDX + TP plates: O, R350-8; $\square$, R650-4; and $\square$, strains of low TP-resistance. (b) Spontaneously-arising RD isolates were selected from the TP-resistant spore segregants: $O$, R350-8 segregant; $O$, R80 segregant $\left(\right.$ THP $\left.^{\mathrm{R}} 2-2\right)$; $\square, \mathrm{R} 650-4$ segregant; and $\square$, the second R80 segregant $\left(t h p^{\mathrm{R}} 4\right)$. A RD isolate was selected from a parental strain, X2180-1B $(\triangle)$. [Spontaneously-arising RD isolates were used because RC segregants were rapidly converted to RD cells by the TP while the control cells (in tubes without TP) remained RC. In this case growth in controls and in tubes containing TP could not be directly compared since RC and RD cells had very different growth rates and yields in GSC.]

resistant. In the quantitative growth-inhibitory assay, $\mathrm{R} 80$ fell into the highly resistant group (see below).

\section{Genetic basis of TP-resistant phenotypes}

To establish whether the TP-resistant phenotype of the mutants was under nuclear control, we made a preliminary cross of each representative mutant with a $\mathrm{RC}$ wild-type yeast. The resulting hybrids were sporulated and individual spore clones were examined for their TP resistance (see Methods). All the crosses showed simple segregation patterns of resistant and sensitive phenotypes in qualitative tests (see next section). To establish whether the resistant segregants retained the same quantitative level of resistance as the mutants, the resistant spores were further examined in the growth-inhibitory assay.

Each genetic cross was carried out with a RC partner and all the segregants were RC, suggesting that the original RD phenotypes were typical mitochondrial $r \mathrm{ho}^{-}$strains (Dujon, 1981). Since RC cells showed complex behaviour in the quantitative growth-inhibitory assay (see legend to Fig. 1), we first selected spontaneous RD colonies from each of the TP-resistant gene segregants to be tested. The TP resistance response of the RD gene segregants is shown in Fig. 1(b). A resistant segregant from R350-8 closely resembled the mutant (Fig. $1 a$ ) in its level of 
Table 2. Genetic analysis of recessive thp ${ }^{\mathrm{R}}$ genes

The parental strains $\left(t h p^{\mathrm{R}}+\right)$ used in the crosses were as follows: crosses $\mathrm{I}(\mathrm{A})$ and $\mathrm{II}(\mathrm{A}), \mathrm{X} 2180-1 \mathrm{~B}$; cross III, X2180-1A; and cross IV, both X2180-1A and X2180-1B. Segregation of the TP-resistant phenotype was determined on MIN media containing 0, 24, 59 and/or $118 \mu \mathrm{M}$-TP. Results were recorded after positive and negative controls showed growth or no growth respectively (3-5 $\mathrm{d}$ in the dark at $30^{\circ} \mathrm{C}$ ).

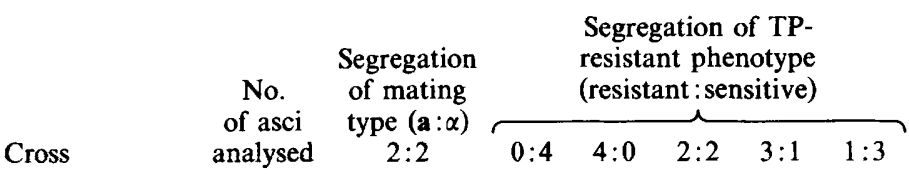
(A) $t h p^{\mathrm{R}} 2-X \times t h p^{\mathrm{R}}+$
(B) $t h p^{\mathrm{R}} 2-X \times t h p^{\mathrm{R}} 2-X$
(C) $t h p^{\mathrm{R}} 2-X \times t h p^{\mathrm{R}} 2-Y$
(D) $t h p^{\mathrm{R}} 2-X \times \operatorname{th} p^{\mathrm{R}} 3$

12
8
9
18

II. $t h p^{\mathrm{R}} 2-Y$

(A) $t h p^{\mathrm{R}} 2-Y \times t h p^{\mathrm{R}}+\quad 9$

(B) $t h p^{\mathrm{R}} 2-Y \times t h p^{\mathrm{R}} 2-Y$

III. $t h p^{\mathrm{R}} 3$

$$
t h p^{\mathrm{R}} 3 \times t h p^{\mathrm{R}}+
$$

IV. Control $t h p^{\mathbf{R}}+\times t h p^{\mathbf{R}}+$

12
8
9
18

$\begin{array}{rrrrr}0 & 0 & 10 & 1 & 1 \\ 0 & 8 & 0 & 0 & 0 \\ 0 & 9 & 0 & 0 & 0 \\ 0 & 5 & 2 & 11 & 0\end{array}$

$\begin{array}{rrrrrr}9 & 0 & 0 & 9 & 0 & 0 \\ 11 & 0 & 11 & 0 & 0 & 0 \\ 8 & 0 & 0 & 8 & 0 & 0 \\ 5 & 5 & 0 & 0 & 0 & 0\end{array}$

TP resistance. A similar result was seen with the gene segregating from R650-4 except that the segregant was more sensitive at high concentrations $(24 \mu \mathrm{M})$ of TP. This increased sensitivity was also seen with some clones of R650-4. In both R350-8 and R650-4 then, the mutant phenotype was recovered quantitatively in gene segregants.

R80 was shown to be a double mutant harbouring two TP resistance genes (see next section). One of the resistant genes from $\mathrm{R} 80$ conferred a high level of resistance in the growth-inhibitory assay (Fig. $1 b$ ); the second resistant gene conferred only slight resistance to TP in the growthinhibitory assay, but grew in the presence of high concentrations of TP $(50 \mu \mathrm{M})$ on solid medium.

Previously, we described another TP-resistant mutant (KP24) isolated following UV mutagenesis (Roth et al., 1978). A resistant segregant from KP24 had a high level of TP resistance in the growth-inhibitory assay similar to that seen with KP24 (results not shown).

In summary, the TP resistance levels seen in the original mutants were quantitatively retained in the gene segregants. The results also indicated that the level of TP resistance in a mutant was not dependent on the interaction of numerous resistance genes.

\section{Segregation patterns of the TP-resistant phenotypes}

Segregation of the TP-resistant phenotypes was tested by mating each mutant with an appropriate TP-sensitive parental strain followed by sporulating and dissecting the resulting hybrids. Only asci showing normal $2: 2$ segregation for mating type were used to evaluate segregation of the dye-resistant phenotype. In addition, uniformity in the parental (sensitive) response to TP was documented in a control cross between X2180-1A and X2180-1B; the TPsensitive phenotype segregated in the expected $0: 4$ (resistant : sensitive) ratio (Table 2, cross IV).

$R 350-8 \times X 2180-1 B$. Of the 12 spore tetrads from the cross involving the highly resistant mutant, 10 showed a $2: 2$ segregation of resistant and sensitive types [Table 2 , cross I (A)]. The segregation patterns in the other two asci suggested that gene conversion events had occurred. The results indicated that the R350-8 phenotype was under the control of a single nuclear gene, tentatively designated $t h p^{\mathrm{R}} 2-X$. Supporting evidence was obtained by backcrossing a resistant spore segregant to R350-8; TP resistance segregated 4:0 (resistant :sensitive), as expected in a cross involving a single allele [Table 2 , cross I (B)]. 
R650-4 $\times X 2180-1 A$. In the cross involving the mutant of moderate TP resistance, 8 asci out of 8 tested gave a $2: 2$ segregation of resistant and sensitive types [Table 2, cross (III)]. It was concluded that the R650-4 phenotype was under the control of a single nuclear gene, tentatively designated $t h p^{\mathrm{R}} 3$. When a resistant spore segregant was backcrossed to R650-4, very low levels of sporulation occurred $(2 \%)$; we made no attempt to examine the diploids for possible segregation.

$R 80 \times X 2180-1 A$. In the cross involving $\mathrm{R} 80$, spores with a high resistance (like $\mathrm{R} 80$ ) and intermediate resistance to the dye were obtained as well as spores with the sensitive, wild-type response. This result suggested that two genes were segregating. When the same cross was analysed on ACE + TP medium, the pattern of segregation suggested a single gene segregation. In summary, the following phenotypes were distinguished among the spore segregants:

\begin{tabular}{|c|c|c|}
\hline $\mathrm{MIN}+\mathrm{TP}$ & $\mathrm{ACE}+\mathrm{TP}$ & Presumptive genotype \\
\hline (1) Weak growth & No growth & $\operatorname{th} p A^{\mathrm{r}} \operatorname{th} p B^{s}$ \\
\hline (2) Weak growth & Growth & $\operatorname{thp} A^{\mathrm{s}} \operatorname{th} p B^{\mathrm{r}}$ \\
\hline (3) Heavy growth & Growth & thp $A^{\mathrm{r}}$ thp $B^{\mathrm{r}}$ \\
\hline (4) No growth & No growth & $\operatorname{th} p A^{\mathrm{s}} \operatorname{th} p B^{\mathrm{s}}$ \\
\hline
\end{tabular}

To account for the results, we proposed that the R80 phenotype was the result of two mutations. One conferred some TP resistance but did not affect the ability of the dye to convert cells from RC to RD (phenotype 1). The second prevented the RC to RD conversion as well as providing TP resistance (phenotype 2). Phenotype 3 represented the R80 double mutant response and phenotype 4 was the wild-type response.

To confirm that phenotype 1 was controlled by a single mutant gene, a spore segregant with this phenotype was crossed with X2180-1B. Out of 9 asci tested, 9 gave the expected $2: 2$ segregation on MIN + TP medium [Table 2, Cross II (A)]. In addition, 9 asci gave a $0: 4$ (resistant : sensitive) segregation on ACE + TP medium, showing the gene had no control over retention of the RC phenotype in the presence of TP. Since a spore segregant controlled by this gene gave a response in the quantitative growth-inhibitory assay similar to a spore segregant from R350-8 (Fig. $1 b$ ), the gene was tentatively designated $t h p^{\mathrm{R}} 2-Y$.

When the spore segregant with phenotype 2 was crossed to a TP-sensitive parental type, 8 out of 9 asci tested segregated $2: 2$ on MIN + TP media and on ACE + TP media [Table 3, Cross II (A)]. This result confirmed that a single resistance gene controlled the ability of R80 to remain $\mathrm{RC}$ while growing in the presence of TP. The gene was tentatively designated $t h p^{\mathrm{R}} 4$.

A cross between spore segregants with phenotypes 1 and 2 was carried out [Table 3, cross II (E)]. The resultant segregation pattern of the asci tested on MIN + TP medium was typical of a two gene segregation: $4: 0$ (resistant : sensitive), $2: 2$ and $3: 1$. Furthermore, in spore segregants containing both $t h p^{\mathrm{R}} 2-Y$ and $t h p^{\mathrm{R}} 4$, the R80 phenotype reappeared.

Finally, Roth et al. (1978) have established that TP-resistance in the mutant KP24 is controlled by a single nuclear gene, redesignated $T H P^{\mathrm{R}} 1$ in this study [Table 3 , cross I (A)].

In summary, we were able to show that mutants of high (R350-8) and moderate (R650-4) levels of resistance to TP were controlled by single nuclear genes. Another mutant (R80), resistant to TP under conditions requiring normal respiratory metabolism, was found to be under the control of two separate nuclear genes. Mutation in one of the genes conferred a high resistance to TP in a growth-inhibitory assay; the other mutation permitted growing cells to remain $R C$ in the presence of high concentrations of TP on ACE medium.

\section{Determination of the actual number of resistance genes}

To establish the number of resistance genes represented by the various mutants, we performed standard complementation tests and tetrad analyses. First, dominance or recessiveness of the resistance genes was determined. Two of the resistance genes were recessive $\left(t h p^{\mathrm{R}} 2, t h p^{\mathrm{R}} 3\right)$ and two were dominant $\left(T H P^{\mathrm{R}} 1, T H P^{\mathrm{R}} 4\right)$.

Allelism among the recessive $t h p^{\mathrm{R}}$ genes was examined in complementation tests. From the data presented in Tables 2 and 4, two recessive resistance genes were identified. One gene, 
Table 3. Genetic analysis of dominant THP $P^{\mathrm{R}}$ genes

The parental strains $\left(t h p^{R}+\right)$ used in the crosses were as follows: cross I(A), A364A and cross II(A), X2180-1B. Segregation of the TP-resistant phenotype in the THP 1 crosses was determined on COMP media containing $0,24,59$ and/or $118 \mu \mathrm{M}$-TP. The $T H P^{R} l$ gene segregant (KP42-7) required adenine, histidine, lysine, tyrosine and leucine for growth. Segregation in the THP 4 crosses was scored on MIN and ACE media containing 24 and/or $50 \mu \mathrm{M}$-TP. Crosses not examined on ACE + TP are marked with a dash. Results were recorded as described in Table 2.

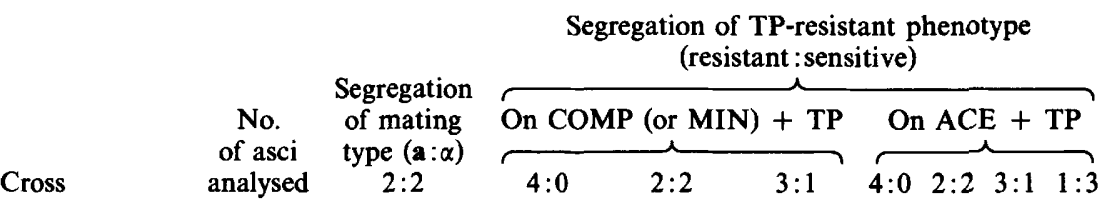

I. $T H P^{\mathrm{R}} 1$

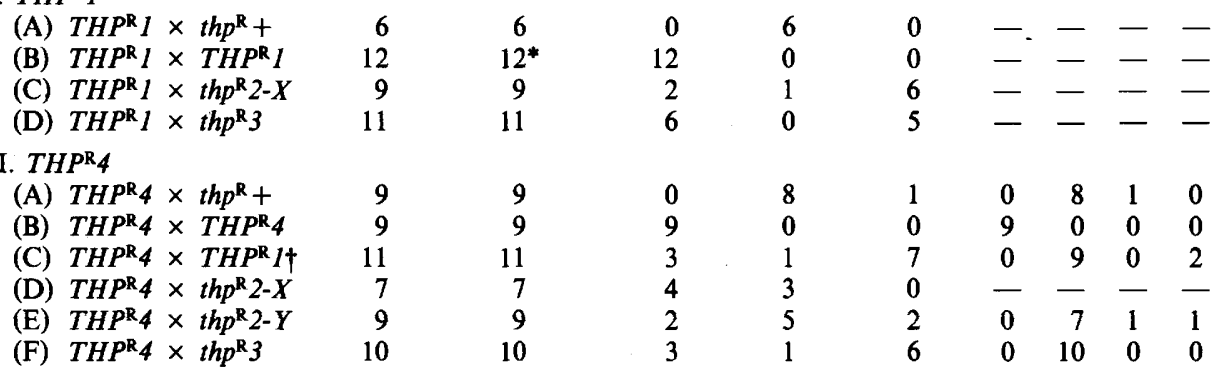

* Refers to segregation of leu-1 from heterozygous hybrids rather than mating type; cross from Roth et al. (1978).

$\dagger$ Cross tested on ACE + TP medium supplemented with L-tyrosine.

Table 4. Complementation analysis of recessive thp ${ }^{\mathrm{R}}$ genes

Diploids containing two recessive $t h p^{\mathrm{R}}$ genes were tested for their ability to grow on MIN + TP $(24 \mu \mathrm{M})$ medium. Results were read after $4 \mathrm{~d}$ incubation in the dark at $30^{\circ} \mathrm{C}$. + , Growth (non-complementation); -, no growth (complementation).

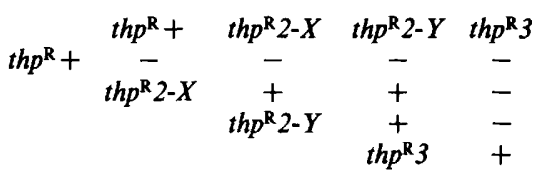

$\operatorname{th} p^{\mathrm{R}} 2-1\left(t h p^{\mathrm{R}} 2-X\right)$, controlled the phenotype of the highly resistant mutant, R350-8; an allele, $\operatorname{th} p^{\mathrm{R}} 2-2\left(\operatorname{th} p^{\mathrm{R}} 2-Y\right)$, was one of the genes in the highly resistant mutant, $\mathrm{R} 80$. The second recessive resistance gene, $t h p^{\mathrm{R}} 3$, was present in the mutant of moderate TP resistance, R650-4.

Tetrad analysis was carried out on a diploid containing the dominant $T H P^{\mathrm{R}}$ genes, $T H P^{\mathrm{R}} 4$ and $T H P^{\mathrm{R}} 1$. The spore tetrads were tested for TP resistance or sensitivity on COMP $+\mathrm{TP}$ medium as one of the gene segregants used in the cross had certain auxotrophic requirements (see legend to Table 3). The data in Table 3 [cross II (C)] indicated that two genes were segregating. In addition, in 9 out of the 11 asci the ability to grow on ACE + TP medium segregated $2: 2$, indicating that only one of the dominant resistance genes permitted cells to remain RC while growing in the presence of TP. The dominant resistance gene from the UVinduced mutant (KP24) was designated $T H P^{\mathrm{R}} 1$, and the dominant gene from $\mathrm{R} 80$ that permitted growth on ACE + TP medium was designated $T H P^{\mathrm{R}} 4$. Finally, tetrad analyses were carried out between the dominant and recessive resistance genes to further confirm their individuality. The data in Table 3 demonstrated that four separate nuclear genes, two recessive and two dominant, controlled the TP-resistant phenotypes in the four mutants analysed (Table 1). 


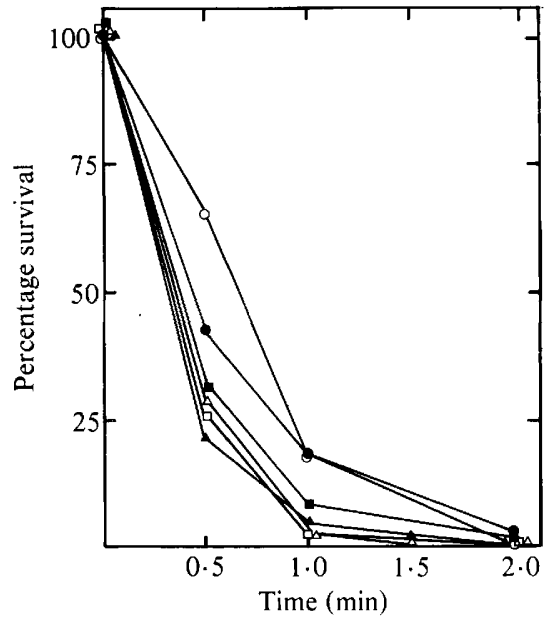

Fig. 2. Photodynamic action of TP on the RD thp $p^{\mathrm{R}} 2-1$ mutant and its TP-induced RD thp $p^{\mathrm{R}}+$ parent. Washed, stationary phase cells were incubated with $24 \mu \mathrm{M}$-TP in $50 \mathrm{mM}$-phosphate buffer (pH 6.8) for $1 \mathrm{~h}$ in the dark $\left(30^{\circ} \mathrm{C}\right.$, shaken at 300 r.p.m. $)$. Dye-treated cells were then illuminated $(2 \cdot 4 \times$ $\left.10^{2} \mathrm{~J} \mathrm{~m}^{-2} \mathrm{~s}^{-1}\right)$ under the following conditions: in the presence of buffer $+\operatorname{TP}(O, O)$; in buffer without TP $(\square, \square)$; and after an additional $15 \mathrm{~min}$ dark incubation in buffer followed by resuspension in fresh buffer $(\Lambda, \triangle)$. The filled symbols represent the $t h p^{\mathbb{R}} 2-1$ mutant and the open symbols represent the thp $p^{\mathrm{R}}+$ strain.

\section{Photodynamic effect of TP in the resistant mutants}

In addition to its growth inhibitory effects, TP at low concentration acts as a photodynamic sensitizer. It is possible that the TP-sensitized photodynamic response of yeast cells could be modified by the resistance mutation, since the resistance to TP could arise by any one or more of the following mutational changes: (1) decreased dye uptake; (2) increased inactivation of the dye; and (3) decreased ability to bind the dye to the sensitive target(s). Any alteration involving mechanisms 1 and 2 could result in mutants more resistant than the parental strain to the photosensitizing effect of the dye; however, mechanism 3 could only result in resistance to the photosensitizing effect if the growth inhibitory target coincided with a photodynamic target. We therefore tested the mutants for their photodynamic response. To measure photodynamic killing, stationary phase cultures $(72 \mathrm{~h})$ were harvested, washed, and incubated in buffer containing $24 \mu \mathrm{M}$-TP for $1 \mathrm{~h}$ in the dark to permit dye uptake and binding (Micheler \& Lochmann, 1971). After the dark incubation, dye-treated cells were handled in one of three ways: (1) left in the buffer + TP solution; (2) harvested and resuspended in fresh buffer without TP; or (3) harvested and resuspended in fresh buffer without TP, re-incubated for $15 \mathrm{~min}$ in the dark, then harvested and resuspended in fresh buffer for a second time. The treated cells were then exposed to a photo-flood lamp $\left(2.4 \times 10^{2} \mathrm{~J} \mathrm{~m}^{-2} \mathrm{~s}^{-1}\right)$; samples were taken at timed intervals to determine viability.

The three methods of handling the dye-treated yeast were designed to yield different information about TP photosensitivity. The first assay indicated whether TP-treated cells were light-sensitive; however, it did not distinguish between photokilling by exogenous or endogenous dye. The second assay eliminated exogenous dye, so any photokilling in this assay would be related to TP taken up and bound by the yeast. The last assay determined whether the dye was easily removed from the cells.

Mutant thp ${ }^{\mathrm{R}} 2-1$. The photosensitizing effects of TP on the RD, thp $p^{\mathrm{R}} 2-1$ mutant and a TPinduced RD strain of parental phenotype were compared. A RD strain was used as the control rather than the original RC parent as previous work has shown that the RD phenotype, by itself, often increases the photosensitivity of a cell to TP (Roth et al., 1978). When the yeast were illuminated in the presence of TP, the thp $p^{\mathrm{R}} 2-1$ mutant was slightly more sensitive $(1.5 \times)$ than 


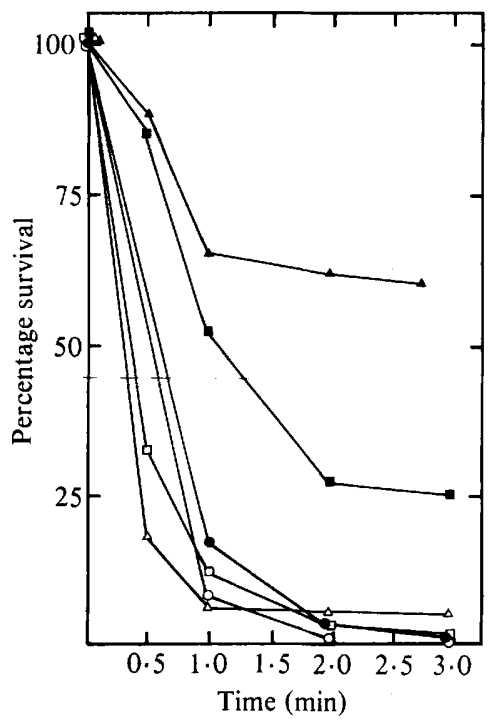

Fig. 3

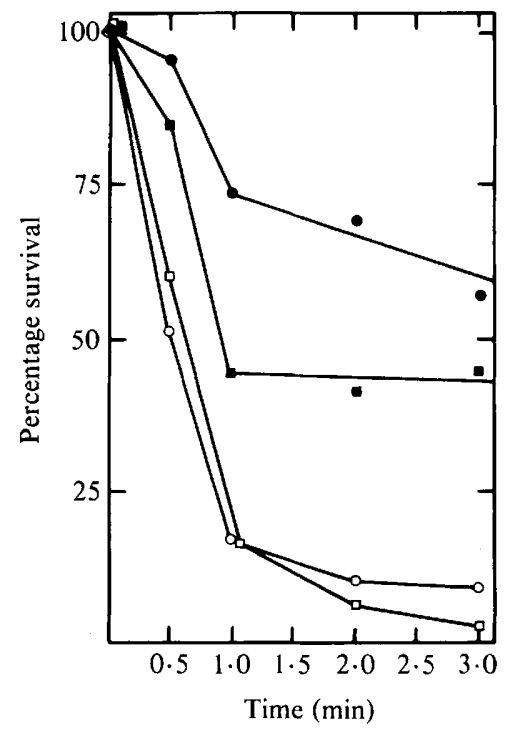

Fig. 4

Fig. 3. Photodynamic action of TP on the RC thp double mutant, $\mathrm{R} 80$, and the $\mathrm{RC}$ thp $p^{\mathrm{R}}+$ parent, X2180-1B. Cells were exposed to $24 \mu \mathrm{M}-\mathrm{TP}$ in the dark as described for Fig. 2. The assays were carried out on dye-treated cells under the following conditions: in the presence of buffer $+\mathrm{TP}(\mathbf{O}, \mathrm{O})$; in buffer without TP ( $\square, \square)$; and after an additional 15 min dark incubation in buffer followed by resuspension in fresh buffer $(\Delta, \triangle)$. Illumination intensity was constant at $2 \cdot 4 \times 10^{2} \mathrm{~J} \mathrm{~m}^{-2} \mathrm{~s}^{-1}$. The filled symbols represent the R80 mutant and the open symbols represent X2180-1B.

Fig. 4. TP photosensitivity of the R80 mutant and its two gene segregants (thp $p^{\mathrm{R}} 2-2$ and $\left.T H P^{\mathrm{R}} 4\right)$ as well as the parental strain (X2180-1B). Cells were exposed to $24 \mu \mathrm{M}$-TP in the dark as described for Fig. 2. The assay was carried out on dye-treated cells following an additional $15 \mathrm{~min}$ dark incubation in buffer and resuspension in fresh buffer. Illumination intensity was constant at $2.4 \times 10^{2} \mathrm{~J} \mathrm{~m}^{-2} \mathrm{~s}^{-1}$., $\mathrm{R} 80$; O, X2180-1B; $\square, T H P^{\mathrm{R}} 4$ segregant; and $\square, t h p^{\mathrm{R}} 2-2$ segregant.

the parent at the earliest illumination time; however, both strains showed the same photodynamic response to the dye after additional illumination (Fig. 2). Since TP was present during illumination in this assay, a possibility existed that both strains were inactivated by a light-induced interaction of exogenous dye with the cells.

To determine whether exogenous dye was the cause of the observed photosensitivity, the mutant and parental strains were illuminated in the absence of TP and showed no significant differences in their survival curves (Fig. 2). However, the two strains were more photosensitive than cells illuminated in the presence of TP. This effect had been noted previously with other yeast strains and was attributed to a quenching effect of the exogenous TP (Micheler, 1972).

Since TP enters yeast cells even after a diffusion equilibrium has been reached it was concluded that the dye is internally bound (Micheler \& Lochmann, 1971). It is possible, then, that a resistance mutation could alter the binding of internal TP. To determine whether this had occurred in the thp $p^{\mathrm{R}} 2-1$ mutant, cells exposed to TP for $1 \mathrm{~h}$ in the dark were resuspended in buffer without TP and reincubated in the dark for $15 \mathrm{~min}$. The cells were then placed in fresh buffer and illuminated, the idea being that any loosely bound or unbound dye would be lost from the cells during the $15 \mathrm{~min}$ buffer incubation. In this assay, the TP photosensitivity of $t h p^{\mathrm{R}} 2-1$ and $t h p^{\mathrm{R}}+$ cells was essentially the same at all time periods tested (Fig. 2), indicating the dye was bound firmly in both strains. This fact was further supported by the finding that cells incubated in buffer $(15 \mathrm{~min})$ remained as photosensitive as cells illuminated immediately after resuspension in buffer.

Mutant thp $p^{\mathrm{R}}$. The RD thp $^{\mathrm{R}} 3$ mutant was then examined; again the mutant was compared to a TP-induced RD parental strain. In the three different assays described above, the $t h p^{\mathrm{R}} 3$ mutant 
showed the same photosensitivity as the parental strain; the survival curves were very similar to those seen in Fig. 2.

Mutant $T H P^{\mathrm{R}} 1$. When the UV-induced $T H P^{\mathrm{R}} 1$ mutant was compared to its parent (A364A) in the assays (types 2 and 3, above) both strains were equally photosensitive under comparable assay conditions. Thus, the TP-sensitized photodynamic response of the $T H P^{\mathrm{R}} 1, \operatorname{thp}^{\mathrm{R}} 2-1$ and $t h p^{\mathrm{R}} 3$ mutants was not modified by their resistance mutations.

Mutant $T H P^{\mathrm{R}} 4$, thp $p^{\mathrm{R}} 2-2$. Since the $\mathrm{R} 80$ mutant was isolated as a RC strain, its TP photosensitivity was compared directly to its RC parent, X2180-1B. In the presence of the dye (assay 1), very little difference was seen in their photodynamic response to TP (Fig. 3). In both strains, most of the survivors of the photosensitization were RD, indicating that TP had entered the cells and affected the mitochondrial genome.

When the R80 mutant and parental strain were assayed in buffer (assay 2), the mutant was markedly resistant to the photosensitizing effects of TP (Fig. 3). This result suggested that R80 either took up less TP or bound it differently than X2180-1B during the dark incubation period. Under the conditions of assay 3, which involved incubation (extraction) for $15 \mathrm{~min}$ in buffer after TP-exposure, $\mathbf{R} 80$ became even more resistant to TP than the wild-type. The survival curve reached a plateau after only $35 \%$ of the cells had been killed (Fig. 3). A similar plateau was seen with the parental strain, but not until $95 \%$ of the cells had been killed. It appeared that the R80 mutant had either a reduced ability to take up or perhaps to bind TP when compared to the parental strain.

Since R80 was a double mutant, it was of interest to determine whether one or both of the resistance genes controlled the reduced photosensitivity to TP. We found (Fig. 4) that a THP 4 segregant was much more resistant than a thp $2-2$ segregant although not as resistant to the photosensitizing effects of TP as the double mutant.

In summary, mutants representing three TP resistance genes were not altered in their photodynamic response to TP when compared to their parental strains. A double mutant, $\mathbf{R} 80$, was resistant to the photodynamic effects of the dye and the resistance appeared to be controlled by one of its genes, $T H P^{\mathrm{R}} 4$. Preliminary diagnostic assays indicated this resistance mutation may affect TP uptake/binding.

We thank Mr Reiner Kloth for assistance in the early stages of this work and Mr S. Sadin of EM Laboratories, Elmsford, New York for thiopyronine.

\section{REFERENCES}

Dujon, B. (1981). Mitochondrial genetics and functions. In The Molecular Biology of the Yeast Saccharomyces, Life Cycles and Inheritance, pp. 505-635. Edited by J. N. Strathern, E. W. Jones \& J. R. Broach. New York: Cold Spring Harbor Laboratory.

FARBER, E. M. (1980). Psoralen and ultraviolet A (PUVA) - a critique. Journal of the American Academy of Dermatology 2, 342-344.

Lochmann, E.-R., Herrmann, C., Pietsch, I. \& Micheler, A. (1976). Distribution of $\left[{ }^{3} \mathrm{H}\right]$ thiopyronine in yeast cells (Saccharomyces cerevisiae). Zeitschrift für Naturforschung 31C, 481-483.

LOChMANN, E.-R., KÄUfeR, N., SchÜTZE, S. \& KREUTZFELDT, C. (1981). Thiopyronine-sensitized photodynamic effect on RNA synthesis in Saccharomyces cells in vivo. International Journal of Radiation Biology 40, 1-9.

MARQUARDT, H. \& VON LAER, U. (1966). Nichtmutagenität von Thiopyronin in einem Vorwärtsund Rückwärtsmutationssystem der Hefe. Die $\mathrm{Na}$ wissenschaften 53, 185.

MICHELER, A. (1972). Untersuchungen zum molekularen
Mechanismus des photodynamischen Effekts. Ph.D. thesis, Freie Universität Berlin, F.R.G.

MicheleR, A. \& LochmanN, E.-R. (1971). Die Aufnahme von Thiopyronin in Saccharomyceszellen XI. Mitteilung über photodynamische Wirkung von Farbstoffen. Studia biophysica 26, 207-214.

Nishiyama-Watanabe, S. (1976). Photodynamic action of thiopyronine on the respiration and fermentation in yeast. International Journal of Radiation Biology 30, 501-509.

Parrish, J. A., FitzPatrick, T. B., TANnenbaum, L. \& PathaK, M. A. (1974). Photochemotherapy of psoriasis with oral methoxsalen and longwave ultraviolet light. New England Journal of Medicine 291, 1207-1211.

ROTH, R. M. \& DAMPIER, C. (1972). Dependence of ribonucleic acid synthesis on continuous protein synthesis in yeast. Journal of Bacteriology 109, 773779.

ROTH, R. M. \& FogEL, S. (1971). A system selective for yeast mutants deficient in meiotic recombination. Molecular and General Genetics 112, 295-305.

Roth, R. M., Papierniak, K. J. \& Anderson, J. M. 
(1978). Mutations in Saccharomyces cerevisiae affecting sensitivity to photodynamic inactivation. Photochemistry and Photobiology 27, 795-798.

ShERMAN, F. \& LAWRENCE, C. W. (1974). Saccharomyces. In Handbook of Genetics, vol. 1, pp. 359-393. Edited by R. C. King. New York: Plenum Press. SPIKES, J. D. (1977). Photosensitization. In The Science of Photobiology, pp. 87-112. Edited by K. C. Smith. New York: Plenum Press.

Stern, R. S., Thibodeau, L. A., Kleinerman, R. A.,
Parrish, J. A., FitzPatrick, T. B. \& 22 ParticipatING INVESTIGATORS. (1979). Risk of cutaneous carcinoma in patients treated with oral methoxsalen photochemotherapy for psoriasis. New England Journal of Medicine 300, 809-813.

Wolff, K., FitzPatrick, T. B., Parrish, J. A., Gschnait, F., Gilchrest, B., HönigsmanN, H., Pathak, M. A. \& Tannenbaum, L. (1976). Photochemotherapy for psoriasis with orally administered methoxsalen. Archives of Dermatology 112, 943-950. 